\title{
Troponin elevation in conditions other than acute coronary syndromes
}

\author{
This article was published in the following Dove Press journal: \\ Vascular Health and Risk Management \\ 2I September 201 I \\ Number of times this article has been viewed
}

\section{Asli Tanindi \\ Mustafa Cemri}

Gazi University Faculty of Medicine, Department of Cardiology, Ankara, Turkey
Correspondence: Asli Tanindi Gazi University Hospital, Department of Cardiology, 06500, Besevler, Ankara, Turkey

Tel +903122025629

Fax +90 312 212 9012

Email aslitanindi@gmail.com

\begin{abstract}
Acute coronary syndromes comprise a large spectrum of clinical conditions ranging from unstable angina pectoris to acute ST-elevation myocardial infarction. Chest pain is usually the major symptom of atherosclerotic heart disease; however, it may be challenging to diagnose correctly, especially in the emergency department, because of the ambiguous way that pain is characterized by some patients. Cardiac troponins are sensitive and specific biomarkers used in the diagnosis of myocardial infarction that are released into the bloodstream when cardiac myocytes are damaged by acute ischemia or any other mechanism. They are the cornerstone for the diagnosis, risk assessment, prognosis, and determination of antithrombotic and revascularization strategies. However, troponin elevation indicates the presence, not the mechanism, of myocardial injury. There are many clinical conditions other than myocardial infarction that cause troponin elevation; thus, the physician should be aware of the wide spectrum of disease states that may result in troponin elevation and have a clear understanding of the related pathophysiology to effectively make a differential diagnosis. This review focuses on causes of troponin elevation other than acute coronary syndromes.
\end{abstract}

Keywords: cardiac troponin, troponin elevation without acute coronary syndrome, differential diagnosis

\section{Introduction}

Acute coronary syndromes constitute a large spectrum of clinical conditions ranging from unstable angina pectoris to acute ST-elevation myocardial infarction. Chest pain is usually the major symptom of atherosclerotic heart disease; however, it may be challenging to diagnose correctly, especially in the emergency department, because of the ambiguous way that some patients characterize their pain. Cardiac serum markers, especially cardiac troponins (cTns), are the cornerstone of the diagnosis, risk assessment, prognosis, and determination of antithrombotic and revascularization strategies. Physicians should be aware of the wide spectrum of disease states that may result in elevation of cTns and have a clear understanding of the related pathophysiology to effectively make a differential diagnosis. This review focuses on causes of troponin elevation other than acute coronary syndromes. Pubmed Central and Cochrane Library were browsed for related topics.

Cardiac troponins consist of three proteins known as $\mathrm{cTnC}, \mathrm{cTnI}$, and $\mathrm{cTnT}^{1}$ that interact with tropomyosin to form the troponin-tropomyosin complex. This complex forms the skeleton of the striated muscle and has a regulatory function in the excitationcontraction coupling of the heart. If heart muscle cells are damaged by acute ischemia or any other mechanism, these proteins are released into the bloodstream. 
The European Society of Cardiology/American College of Cardiology Joint Committee has redefined myocardial infarction (MI) to be an elevation of serum cTn above the 99th percentile of the healthy reference population in the presence of ischemic signs and symptoms. ${ }^{2}$ In addition, a rising and/or falling troponin pattern is an important component of the universal definition of MI. The major limitation of the standard cTn assays is their low sensitivity in the first few hours after MI at the time of the first presentation in the patient due to a delayed increase in the circulating levels of cTns. The diagnosis may take 6-12 hours of monitoring and serial blood sampling, which delays diagnosis and probably increases morbidity and mortality. ${ }^{3}$ To overcome this issue, highly sensitive cTn assays have been developed that can detect cTn levels well below the 99th percentile of the normal reference population. ${ }^{4}$ However, increased sensitivity comes at the cost of decreased specificity. Although the availability of highly sensitive assays allows for the earlier detection of MI, the number of patients with detectable cTn values in the emergency department or other in-hospital settings increases substantially as a result, which challenges the clinician to make a differential diagnosis. With these new assays in particular, nonischemic causes of troponin elevation should be kept in mind since troponin elevation indicates the presence, not the mechanism, of myocardial injury.

\section{Noncardiac causes of troponin elevation \\ Chronic renal failure}

Acute coronary syndromes are frequently observed in renal failure; however, the use of troponin for diagnosis is inconvenient since cTn levels may be elevated in the absence of an acute ischemic event. ${ }^{5-7}$ Mortality remains high in end-stage renal disease despite dialysis therapy; approximately $50 \%$ of these deaths are due to cardiac causes. ${ }^{8-10}$ Electrocardiography (ECG) may not be reliable in most of these patients because intraventricular conduction defects and left ventricular hypertrophy are very common. Troponins are commonly used as prognostic indicators in end-stage renal disease although troponins and creatinine kinase-myocardial band (CKMB) may show false positivity in this group as mentioned elsewhere. ${ }^{11}$ In acute myocardial injury, slightly elevated troponin levels may be detected but creatinine kinase (CK) and CKMB levels remain in the reference range. This finding is due to the unbound fraction of troponins in the cytoplasm of the cardiac myocytes, which is approximately $6 \%$ of $\mathrm{cTnT}$ and $3 \%$ of $\mathrm{cTnI} .{ }^{12}$ Although it remains to be proven, it is thought that the unbound fraction increases in renal failure.

Some animal experiments have shown that trauma and stress induce the cTnT isoform in skeletal muscle. It is speculated that chronic skeletal muscle damage and inflammation in dialysis patients induce $\mathrm{cTnT}$ in a similar way. ${ }^{13-15}$

Heart failure is also a common comorbidity in renal failure, in which troponins increase without any evidence of ischemia or infarct. ${ }^{16}$

Decreased clearance is another proposed explanation for troponin elevation in renal failure; ${ }^{17}$ however, troponins are large macromolecules like CK, CKMB, and albumin that are cleared by the reticuloendothelial system. Recent studies suggest that cardiac troponins are fragmented into immunoactive particles of $8-25 \mathrm{kDa}$ in length that are quite sensitive to immunoassays. ${ }^{18}$ Although these fragments are small enough to be cleared by healthy kidneys, renal impairment leads to clearance decrease. The healthy human heart is always prone to microloss of cardiac myocytes but, when renal failure is involved, clearance of troponin fragments due to routine myocyte loss is impaired.

In renal failure, cTnT elevation is seen more frequently than cTnI. cTnI is less stable in the blood and is more prone to chemical changes in addition to higher rates of clearance during dialysis; as a result, it is thought to have an advantage over cTnT in patients with renal impairment. ${ }^{19}$

\section{Advanced heart failure}

Patients with acute heart failure/acute pulmonary edema constitute an important proportion of emergency department admissions. Troponin levels may rise without overt ischemia in heart failure..$^{20,21}$ This phenomenon was first reported by Missov and Calzolari. ${ }^{22}$ In another study by the same group, it was concluded that myocyte injury in the chronically damaged myocardium results in damage of the contractile proteins, which consequently causes protein leakage to the circulation. ${ }^{23}$ Sato et al have reported dismal prognoses in patients with nonischemic heart failure with the highest percentile of admission cTnT levels, although they were treated with optimal medical therapy. ${ }^{21}$ This was associated with the ongoing subclinical myocardial damage within the subgroup with the highest admission cTnT levels. Troponin positivity was reported to be $10.4 \%$ and $92 \%$ using standard and highly sensitive cTnT assays, respectively, in 4053 chronic heart failure patients enrolled in the Valsartan Heart Failure Trial (Val-HeFT). ${ }^{24}$ Many studies have reported that troponin can be used as predictor of mortality, especially when ultrasensitive assays are used..$^{25,26}$ 


\section{Cerebrovascular accidents}

\section{Subarachnoid hemorrhage (SAH)}

The cardiac effects of intracardiac bleeding were first defined in 1903 by Cushing as alterations in blood pressure and cardiac rhythm disturbances..$^{27}$ Electrocardiographic manifestations were first mentioned by Byer in $1947 .{ }^{28}$ Several studies since then have shown the effects of hypothalamic stimulation on ECG and the cardiac rhythm in addition to the fact that myocardial injury was not mandatory for manifested electrocardiographic changes. ${ }^{29}$ Earlier, it was believed that atherosclerotic coronary artery disease or coronary vasospasm was the basis of cardiac injury in subarachnoid bleeding, but this was not shown angiographically. Myocardial ischemia secondary to tachycardia and/or hypertension was the other proposed mechanism.

Today, the most widely accepted theory is the "catecholamine hypothesis." 30 Several autopsy studies have revealed petechial subarachnoid bleeding sites and histologically dense eosinophilic transverse bands in the myocardium. This phenomenon is termed "contraction band necrosis" and is detected in both patients with electrocardiographic changes and those with completely normal ECGs. Similar lesions are also detectable in patients with pheochromocytoma or in animal experiments using stellate ganglion stimulation or catecholamine infusion. ${ }^{31}$ An increase in plasma catecholamines of up to $30 \times$ is possible, but it is uncertain whether myocardial necrosis is related to the plasma catecholamine increase or to the catecholamine surge that is locally stimulated by cardiac nerves. It is possible that acute brain injury results in a massive release of norepinephrine from the myocardial sympathetic nerve terminals to the myocardial interstitium, which may subsequently lead to myocyte necrosis and contractile dysfunction in addition to sympathetic nerve terminal damage.

The latest studies have reported the rate of cardiac injury markers as being $20 \%-40 \%$ in the presence of subarachnoid bleeding. ${ }^{30,32}$ Approximately $10 \%$ of these patients have reversible segmental wall motion abnormalities that fit the distribution pattern of the myocardial sympathetic nerve terminals rather than the pattern of coronary artery disease. The most severe form of myocardial injury involving elevated myocardial injury markers is "neurogenic cardiogenic shock" ${ }^{n 3,34}$ accompanied by pulmonary edema.

Among patients with aneurysmal $\mathrm{SAH}$, the subgroup with higher Hunt-Hess scores, which are used to grade the bleeding severity, had higher troponin I levels. ${ }^{35}$
In another study, it was reported that functional recovery of the aneurysmal SAH patients with higher troponin levels was poor, and the sequela rates were higher. ${ }^{36}$ The authors conclude here that $\mathrm{cTn}$ also plays a role in predicting $\mathrm{SAH}$ prognosis.

\section{Ischemic cerebrovascular accident}

Studies investigating troponin release in the course of ischemic cerebrovascular disease have reported contradictory results in contrast to studies on cerebral hemorrhage. Troponin levels were found to be increased and had prognostic significance in some studies ${ }^{37,38}$ but not others. ${ }^{39,40}$ As a result, troponin cannot be reliably used as a prognostic indicator for ischemic cerebrovascular disease. The proposed mechanisms regarding troponin release in the early phase of ischemic cerebrovascular disease include secondary cardioembolic cerebral ischemia related to primary myocardial damage, secondary central nervous system activation to primary cerebral ischemia, and cerebral disease-related heart failure.

\section{Acute pulmonary embolism}

Acute massive or submassive pulmonary embolism is associated with elevated serum cTn levels. ${ }^{41}$ Rates of troponin positivity have been reported as $16 \%-47 \%$ in several studies, and troponin has been proposed as a risk determinant that may help in the decision of performing thrombolysis or embolectomy. ${ }^{42-44}$

Massive pulmonary embolism may cause cardiogenic shock and acute right ventricular dilatation. The sudden increase in oxygen demand of the right ventricle, increase in right ventricle intramural pressure, decrease in cardiac output, and release of endothelial mediators such as tromboxane, serotonin, and endothelin contribute to right ventricular ischemia and damage. ${ }^{45,46}$

\section{Chronic obstructive pulmonary disease (COPD)}

Cardiovascular risk factors and cardiac comorbidity are frequent in patients with COPD. Troponin elevation was found to be an independent predictor of the need for noninvasive mechanical ventilation and mortality in patients who were admitted with acute exacerbation of COPD. ${ }^{47-49}$ The amount of energy and oxygen needed for respiration is increased in the acute exacerbation period; in addition, the left ventricular afterload is increased in relation with more negative intrathoracic pressure. Worsened pulmonary hypertension, hypoxia, and hypercapnia also contribute to myocardial damage during the acute exacerbation period. 


\section{Acute noncardiac critical illness}

The term "critically ill patient" refers to individuals who are hospitalized in intensive care units, patients who are typically elderly with multiple comorbid illnesses ${ }^{50}$ However, some fragile older patients, who live alone or in nursing homes and are referred to emergency departments and subsequently hospitalized, may also be included in this category.

Studies of intensive-care-unit patients report that troponin is elevated in patients with increased myocardial demand due to multiple comorbid conditions, positive end expiration therapy, the need for inotropic support, or high body temperature; these patients typically have higher morbidity and mortality rates. ${ }^{51,52}$ Hypotension, anemia, and microocclusion impair oxygenation. Increased myocardial oxygen demand, increased wall tension, hypertension, tachycardia, pulmonary embolism, or the presence of myocardial toxins in sepsis can cause minor myocardial damage. Troponin can be temporally elevated in some situations, a finding that is related to increased membrane permeability. ${ }^{53}$ The myocardial depressing factors released in sepsis and other inflammatory conditions cause troponin to be fragmented into low molecular weight particles in situ. These fragments are secreted into the circulation in the presence of increased membrane permeability. Since there is no necrosis, the myocyte damage is not permanent. Myocardial depression is completely reversible in patients who recover from sepsis.

\section{Strenuous exercise}

Competitive endurance sports have been suggested to be associated with elevations in cardiac biomarkers, especially cTns. Different human studies in the literature have reported a wide range of rates for troponin elevation, up to as much as $78 \% .{ }^{54}$ Use of different generation assays with different cutoffs is the probable cause of this wide range of results. The pathophysiology and probable clinical impact of cTn elevation have been addressed in many studies, but a consensus does not exist. Middleton et al suggested that the increased myocardial demand related to endurance exercise could physiologically increase the turnover of cardiac troponins. ${ }^{55}$ Another proposal was that stress induces free radical overload, which causes a transient increase in membrane permeability and leads to troponin leakage from the cytosol. ${ }^{56}$ A recent rat study supported this hypothesis in that it was shown that the temporal change in serum cTn was matched by an increase in the concentration of myocardial malondialdehyde, a marker of free radical-related lipid peroxidation. ${ }^{57}$ Exercise-induced dehydration, hemoconcentration, and altered acid-base balance were also reported to be associated with this increased membrane permeability. ${ }^{58}$ Hickman et al suggested that transient ischemia induced the development of blebs on the cytoplasmic membrane, leading to cTn release. ${ }^{59}$ Whatever the mechanism, the kinetics of the asymptomatic cTn release after intense exercise with an early peak and quick normalization is quite different from the elevation pattern observed in acute coronary syndromes. ${ }^{60}$ Exercise duration, exercise intensity, and running distance were the suggested risk factors for cTn elevation; ${ }^{61,62}$ however, it was shown that running even a short distance could result in significant cTn release in untrained individuals. ${ }^{63}$ Troponin elevation was not found to be associated with any functional impairment using either echocardiography or cardiac magnetic resonance imaging. ${ }^{64-66}$ In light of the current knowledge, there seems to be no prognostic implication of troponin elevation.

\section{Direct myocardial trauma}

Direct cardiac trauma may cause troponin elevation due to the impairment of cardiac myocyte integrity. Velhamos et al enrolled 333 patients with direct myocardial contusions to examine the predictive value of troponin levels. ${ }^{67}$ Serial evaluation of ECG and troponin measurements and selective echocardiographic examination revealed that the combined use of ECG and cTnT had a negative predictive value of $100 \%$ for blunt cardiac trauma, whereas $\mathrm{cTnI}$ alone had a negative predictive value of $94 \%$.

\section{Cardiac causes of troponin elevation other than acute coronary syndromes \\ Acute pericarditis}

Although troponins are not found in the pericardium, they may be elevated because of the involvement of the epicardium in the inflammatory process. ${ }^{68,69}$ In addition, some myocardial damage may take place, and the pattern of troponin release in acute pericarditis mimics that of acute coronary syndromes. One should also keep in mind that these two conditions may coexist, meaning that troponins cannot be used for the differential diagnosis of acute coronary syndrome and acute pericarditis. ${ }^{70}$ In contrast to acute coronary syndromes, troponin positivity was not associated with poor prognosis.

\section{Acute inflammatory myocarditis}

Acute myocarditis may mimic MI since chest pain, segmental wall motion abnormalities, and myocardial necrosis proven 
by troponin elevation exist in both conditions. ${ }^{71,72}$ Smith et al reported the rate of troponin positivity as being 34\% in a study population with biopsy-proven myocarditis. ${ }^{73}$ It has also been found that troponin is more sensitive than CKMB and correlates well with the symptoms of heart failure at 1 month after acute myocarditis. How long the troponins remain elevated depends on the inflammation severity.

\section{Tachycardia}

Supraventricular or ventricular tachycardia, atrial fibrillation with high ventricular response, or any other tachycardia may cause troponin elevation by increasing the myocardial oxygen demand without epicardial coronary stenosis. Temporal myocyte damage due to hemodynamic compromise is the mechanism responsible for this phenomenon. ${ }^{74,75}$

Elective cardioversion, using direct current shocks of up to $1370 \mathrm{~V}$, was not associated with significant troponin increase.$^{76}$ However, multiple shocks for ventricular fibrillation during cardiopulmonary resuscitation raise serum troponin levels, which makes non-ST-elevation myocardial infarction diagnoses difficult. ${ }^{77}$

\section{False-positive troponin elevation}

Troponin measurements are rarely prone to false-positive elevation in the absence of cardiac or noncardiac reasons. Fibrin in the specimens or endogenous antibodies interfering with the immunoassays are the most frequent causes. ${ }^{78}$ Endogeneous antibodies include rheumatoid factor or heterophilic antibodies, which develop against animal immunoglobulins. Frequent contact with animals, injection of animal antibodies for some imaging and treatment procedures, immunotherapies, vaccinations, and blood transfusions may cause the production of interfering antibodies in the circulation. ${ }^{79}$ To prevent interference, use of ultracentrifugation is proposed, which has been reported to satisfactorily decrease the rate of false-positive results. ${ }^{78}$ Other strategies include dilution, use of heterophilic blocking tubes, use of immunoglobulin-inhibiting reagents, or precipitation with polyethylene glycol. ${ }^{79}$ Modern immunoassays have been developed through the addition of nonspecific blocking antibodies to prevent interference; regardless, there may still be patients whose conditions exceed the blocking capacity of these immunoassays. ${ }^{80}$

\section{Conclusion}

Although cardiac troponins have been accepted as the gold standard in the diagnosis and risk stratification of acute coronary syndromes, misinterpretation of detectable troponin levels in the emergency department or other in-hospital settings may lead to confusion in terms of diagnosis and choice of suitable therapy options. Physicians should be aware of the nonischemic causes of troponin positivity as well as their pathophysiology and clinical impact in an effort to prevent unnecessary invasive and noninvasive treatments and coronary care unit admissions.

\section{Disclosure}

The authors report no conflicts of interest in this work.

\section{References}

1. Lippi G, Targher G, Franchini M, Plebani M. Genetic and biochemical heterogeneity of cardiac troponins: clinical and laboratory implications. Clin Chem Lab Med. 2009;47(10):1183-1194.

2. Thygesen K, Alpert JS, White HD, et al. Joint ESC/ACCF/AHA/WHF Task Force for the Redefinition of Myocardial Infarction. Universal definition of myocardial infarction. Eur Heart J. 2007;28(20): 2525-2538.

3. Reichlin T, Hochholzer W, Bassetti S, et al. Early diagnosis of myocardial infarction with sensitive cardiac troponin assays. N Engl J Med. 2009;361(9):858-867.

4. Christenson RH, Phillips D. Sensitive and high sensitivity next generation cardiac troponin assays: more than just a name. Pathology. 2011; 43(3):213-219.

5. Landray MJ, Emberson JR, Blackwell L, et al. Prediction of ESRD and death among people with CKD: the Chronic Renal Impairment in Birmingham (CRIB) prospective cohort study. Am J Kidney Dis. 2010; 56(6):1082-1094.

6. McLaurin MD, Apple FS, Falahati A, et al. Cardiac troponin I and CKMB mass to rule out myocardial injury in hospitalized patients with renal insufficiency. Am J Cardiol. 1998;82(8):973-975.

7. Petrovic D, Stojimirovic BB. Cardiac troponins: outcome predictors in hemodialysis patients. J Artif Organs. 2009;12(4):258-263.

8. Goodkin DA, Young EW, Kurokawa K, Prutz KG, Levin NW. Mortality among hemodialysis patients in Europe, Japan, and the United States: case-mix effects. Am J Kidney Dis. 2004;44(Suppl 2):16-21.

9. Schiffrin EL, Lipman ML, Mann JF. Chronic kidney disease: effects on the cardiovascular system. Circulation. 2007;116(1):85-97.

10. Khan NA, Hammelgarn B, Tonelli M. Prognostic value of troponin $\mathrm{T}$ and I among asymptomatic patients with end-stage renal disease: a meta-analysis. Circulation. 2005;112(20):3088-3096.

11. Francis GS, Tang WH. Cardiac troponins in renal insufficiency and other non-ischemic cardiac conditions. Prog Cardiovasc Dis. 2004;47(3): 196-206.

12. Newby K, Christenson RH, Ohman EM: The role of troponins and other markers of myocardial necrosis in risk stratification. In Topol E (editor): Acute Coronary Syndromes. New York: Marcel Dekker Inc; 2001: 329-332.

13. McLaurin MD, Apple FS, Voss EM, et al. Cardiac troponin I, cardiac troponin $\mathrm{T}$ and $\mathrm{CKMB}$ in dialysis patients without ischemic heart disease: evidence of cardiac troponin T expression in skeletal muscle. Clin Chem. 1997;43(6 Pt 1):976-982.

14. Haller C, Zehelein J, Remppis A, Muller-Bardorff M, Katus HA. Cardiac troponin $\mathrm{T}$ in patients with ESRD: absence of expression in truncal skeletal muscles. Clin Chem. 1998;44(5):930-938.

15. Ricchiuti V, Voss EM, Ney A, Odland M, Anderson PA, Apple FS. Cardiac troponin $\mathrm{T}$ isoforms expressed in renal diseased skeletal muscle will not cause false-positive results by the 2 nd generation cardiac troponin $\mathrm{T}$ assay by Boehringer Mannheim. Clin Chem. 1998;44(9):1919-1924.

16. Zümrütdal A, Bakinen O, Uçan H, Atalay HV, Bodur H. Relationship between uremic myopathy and false-positive cardiac troponin $\mathrm{T}$ test. Nephron. 2000;86(4):522-523. 
17. Aviles RJ, Askari AT, Lindahl B, et al. Troponin T levels in patients with acute coronary syndromes with or without renal dysfunction. N Engl J Med. 2002;346(26):2047-2052.

18. Diris JHC, Hackeng CM, Koman JP, et al. Impaired renal clearance explains elevated troponin $\mathrm{T}$ fragments in hemodialysis patients. Circulation. 2004;109(1):23-25.

19. Freda BJ, Tang WH, Van Lente F, Peacock WF, Francis GS. Cardiac troponins in renal insufficiency: review and clinical implications. J Am Coll Cardiol. 2002;40(12):2065-2071.

20. Kawahara C, Tsutamoto T, Nishiyama K, et al. Prognostic role of high-sensitivity cardiac troponin $\mathrm{T}$ in patients with nonischemic dilated cardiomyopathy. Circ J. 2011;75(3):656-661.

21. Sato Y, Nishi K, Taniguchi R, et al. In patients with heart failure and non-ischemic heart disease, cardiac troponin $\mathrm{T}$ is a reliable predictor of long-term echocardiographic changes and adverse cardiac events. J Cardiol. 2009;54(2):221-230.

22. Missov E, Calzolari C. Elevated troponin I in some patients with severe congestive heart failure. J Mol Cell Cardiol. 1995;27:A405.

23. Missov E, Calzolari C, Pau B. Circulating cardiac troponin I in severe congestive heart failure. Circulation. 1997;96(9):2953-2958.

24. Latini R, Masson S, Anand IS, et al. Prognostic value of very low plasma concentrations of troponin $\mathrm{T}$ in patients with stable chronic heart failure. Circulation. 2007;116(11):1242-1249.

25. Tsutamoto T, Kawahara C, Nishiyama K, et al. Prognostic role of highly sensitive cardiac troponin $\mathrm{I}$ in patients with systolic heart failure. $\mathrm{Am}$ Heart J. 2010;159(1):63-67.

26. Manzano-Fernandez S, Boronat-Garcia M, Albaladejo-Oton MD, et al. Complementary prognostic value of Cystatin C, N-terminal pro-B-type natriuretic peptide and cardiac troponin $\mathrm{T}$ in patients with acute heart failure. Am J Cardiol. 2009;103(12):1753-1759.

27. Cushing $\mathrm{H}$. The blood pressure reaction of acute cerebral compression illustrated by cases of intracranial hemorrhage. Am J Med Sci. 1903;125: 1017-1044

28. Byer E, Toth LA, Ashman R. Electrocardiographic changes induced by cooling or warming the inner surface of the dog's ventricle. Am J Physiol. 1947;149(1):264-276.

29. Weinberg SJ, Fuster JM. Electrocardiographic changes produced by localized hypothalamic stimulations. Ann Intern Med. 1960;53:332-341.

30. Tung P, Kopelnik A, Banki N. Predictors of neurocardiogenic injury after subarachnoid hemorrhage. Stroke. 2004;35(2):548-553.

31. Todd GL, Baroldi G, Pieper GM, et al. Experimental catecholamineinduced myocardial necrosis I. Morphology, quantification and regional distribution of acute contraction band lesions. J Mol Cell Cardiol. 1985; 17(4):317-338.

32. Naidech AM, Kreiter K, Janjua N, et al. Cardiac troponin elevation, cardiovascular morbidity and outcome after subarachnoid hemorrhage. Circulation. 2005;112(18):2851-2856.

33. Lazaridis C, Pradilla G, Nyquist PA, Tamargo RJ. Intra-aortic balloon pump counterpulsation in the setting of subarachnoid hemorrhage, cerebral vasospasm, and neurogenic stress cardiomyopathy. Case report and review of the literature. Neurocrit Care. 2010;13(1):101-108.

34. Busani S, Rinaldi L, Severino C, et al. Levosimendan in cardiac failure after subarachnoid hemorrhage. J Trauma. 2010;68(5):E108-E110.

35. Hravnak M, Frangiskakis JM, Crago EA, et al. Elevated cardiac troponin I and relationship to persistence of electrocardiographic and echocardiographic abnormalities after aneurismal subarachnoid hemorrhage. Stroke. 2009;40(11):3478-3484.

36. Miketic JK, Hravnak M, Sereika SM, Crago EA. Elevated cardiac troponin I and functional recovery and disability in patients after aneurismal subarachnoid hemorrhage. Am J Crit Care. 2010;19(6):522-528.

37. Christensen H, Johannesen HH, Christensen AF, Bendtzen K, Boysen G. Serum cardiac troponin I in acute stroke is related to serum cortisol and TNF-alpha. Cerebrovasc Dis. 2004;18(3):194-199.

38. Chalela JA, Ezzeddine MA, Davis L, Warach S. Myocardial injury in acute stroke: a troponin I study. Neurocrit Care. 2004;1(3):343-346.

39. Ay H, Arsava EM, Saribaş O. CKMB elevation after stroke is not cardiac in origin: comparison with c TnT levels. Stroke. 2002;33(1):286-289.
40. Etgen T, Baum H, Sander K, Sander D. Cardiac troponins and NT-pro-brain natriuretic peptide in acute ischemic stroke do not relate to clinical prognosis. Stroke. 2005;36(2):270-275.

41. Inbar R, Shoenfeld Y. Elevated cardiac troponins: the ultimate marker for myocardial necrosis, but not without a differential diagnosis. Isr Med Assoc J. 2009;11(1):50-53.

42. Mehta NJ, Jani K, Khan IA. Clinical usefulness and prognostic value of elevated cardiac troponin 1 levels in acute pulmonary embolism. $\mathrm{Am}$ Heart J. 2003;145(5):821-825.

43. Yalamanchili K, Sukhija R, Aronow WS, Sinha N, Fleisher AG, Lehrman SG. Prevalance of increased cardiac troponin 1 levels in patients with or without acute pulmonary embolism and relation of increased cardiac troponin I levels with in hospital mortality in patients with acute pulmonary embolism. Am J Cardiol. 2004;93(2):263-264.

44. Moores L, Aujesky D, Jimenez D, et al. Pulmonary Embolism Severity Index and troponin testing for the selection of low-risk patients with acute symptomatic pulmonary embolism. J Thromb Haemost. 2010; $8(3): 517-522$.

45. Meyer T, Binder L, Hruska N, Luthe H, Buchwald AB. Cardiac troponin I elevation in acute pulmonary embolism is associated with right ventricular dysfunction. J Am Coll Cardiol. 2000;36(5):1632-1636.

46. Pruszczyk P, Bochowicz A, Torbicki A, et al. Cardiac troponin T monitoring identifies high-risk group of normotensive patients with acute pulmonary embolism. Chest. 2003;123(6):1947-1952.

47. Baillard C, Boussarsar M, Girou E, et al. Cardiac troponin I in patients with severe exacerbation of COPD. Intensive Care Med. 2003;29(4): 584-589.

48. Martins CS, Rodrigues MJ, Miranda VP, Nunes JP. Prognostic value of cardiac troponin I in patients with COPD acute exacerbation. Neth J Med. 2009;67(10):341-349.

49. Fruchter O, Yigla M. Cardiac troponin-I predicts long-term mortality in chronic obstructive pulmonary disease. COPD. 2009;6(3):155-161.

50. Gunnewiek JM, Van Der Hoeven JG. Cardiac troponin elevations among critically ill patients. Curr Opin Crit Care. 2004;10(5):342-346.

51. Guest TM, Ramanathan AV, Tuteur PG, Schechtman KB, Ladenson JH, Jaffe AS. Myocardial injury in critically ill patients. A frequently unrecognized complication. JAMA. 1995;273(24):1945-1949.

52. Koshkina EV, Krasnosel'skii Mia, Fedorovskii NM, et al. Diagnostic value of cardiac troponin T increase in critically ill patients. Anesteziol Reanimatol. 2009;6:42-46.

53. Amman P, Maggiorini M, Bertel O, et al. Troponin as a risk factor for mortality in critically ill patients with acute coronary syndrome. $J \mathrm{Am}$ Coll Cardiol. 2003;41(11):2004-2009.

54. Shave R, George KP, Atkinson G, et al. Exercise-induced cardiac troponin T release: a meta-analysis. Med Sci Sports Exerc. 2007;39(12): 2099-2106.

55. Middleton N, George K, Whyte G, Gaze D, Collinsom P, Shave R. Cardiac troponin $\mathrm{T}$ release is stimulated by endurance exercise in healthy humans. J Am Coll Cardiol. 2008;52(22):1813-1814.

56. Neumayr G, Pfister R, Mitterbauer Get al. Effect of the "Race Across The Alps" in elite cyclists on plasma cardiac troponins I and T. Am J Cardiol. 2002;89(4):484-486.

57. Nie J, Close G, George KP, Tong TK, Shi Q. Temporal association of elevations in serum cardiac troponin $\mathrm{T}$ and myocardial oxidative stress after prolonged exercise in rats. Eur J Appl Physiol. 2010;110(6): 1299-1303.

58. Regwan S, Hulten EA, Martinho S, et al. Marathon running as a cause of troponin elevation: a systematic review and meta-analysis. $J$ Interv Cardiol. 2010;23(5):443-450.

59. Hickman PE, Potter JM, Aroney C, et al. Cardiac troponin may be released by ischemia alone, without necrosis. Clin Chim Acta. 2010; 411(5-6):318-233.

60. Shave R, George K, Gaze D. The influence of exercise upon cardiac biomarkers: a practical guide for clinicians and scientists. Curr Med Chem. 2007;14(13):1427-1436

61. Fortescue EB, Shin AY, Greenes DS, et al. Cardiac troponin increases among runners in the Boston Marathon. Ann Emerg Med. 2007;49(2):137-143. 
62. Neilan TG, Januzzi JL, Lee-Lewandrowski E, et al. Myocardial injury and ventricular dysfunction related to training levels among nonelite participants in the Boston marathon. Circulation. 2006;114(22):2325-2333.

63. Mingels AM, Jacobs LH, Kleijnen VW, et al. Cardiac troponin T elevations, using highly sensitive assay, in recreational running depend on running distance. Clin Res Cardiol. 2010;99(6):385-391.

64. Whyte G, George K, Shave R, et al. Impact of marathon running on cardiac structure and function in recreational runners. Clin Sci (Lond). 2005;108(1):73-80.

65. George K, Whyte G, Stephenson C, et al. Postexercise left ventricular function and cTnT in recreational marathon runners. Med Sci Sports Exerc. 2004;36(10):1709-1715.

66. O'Hanlon R, Wilson M, Wage R, et al. Troponin release following endurance exercise: is inflammation the cause? A cardiovascular magnetic resonance study. J Cardiovasc Magn Reson. 2010;12:38.

67. Velhamos GC, Karaiskakis M, Salim A, et al. Normal electrocardiography and serum troponin 1 levels preclude the presence of clinically significant blunt cardiac injury. J Trauma. 2003;54(1):45-50.

68. Imizao M, Demichelis B, Cecchi E, et al. Cardiac troponin I in acute pericarditis. J Am Coll Cardiol. 2003;42(12):2144-2148.

69. Bonnefoy E, Godon P, Kirkorian G, Fatemi M, Chevalier P, Touboul P. Serum cardiac troponin I and ST segment elevation in patients with acute pericarditis. Eur Heart J. 2000;21(10):832-836.

70. Korff S, Katus HA, Giannitsis E. Differential diagnosis of elevated troponins. Heart. 2006;92(7):987-993.

71. Dec GW Jr, Waldman H, Southern J, et al. Viral myocarditis mimicking acute myocardial infarction. J Am Coll Cardiol. 1992;20(1):85-89.
72. Narula J, Khaw BA, Dec GW Jr et al. Brief report: recognition of acute myocarditis masquerading as acute myocardial infarction. $N$ Engl J Med. 1993;328(2):100-104.

73. Smith SC, Landenson JH, Mason JW, et al. Elevations of cardiac troponin I associated with myocarditis. Experimental and clinical correlates. Circulation. 1997;95(1):163-168.

74. Redfearn DP, Ratib K, Marshall HJ, Griffith MJ. Supraventricular tachycardia promotes release of troponin I in patients with normal coronary arteries. Int J Cardiol. 2005;102(3):521-522.

75. Patane S, Marte F, Di Bella G. Abnormal troponin I levels after supraventricular tachycardia. Int J Cardiol. 2009;132(2):e57-e59.

76. Neumayr G, Hagn C, Ganzer H, et al. Plasma levels of cardiac troponin T after electrical cardioversion of atrial fibrillation and atrial flutter. $\mathrm{Am}$ J Cardiol. 1997;80(10):1367-1369.

77. Müllner M, Hirschl MM, Herkner H, et al. Creatine kinase - mb fraction and cardiac troponin $\mathrm{T}$ to diagnose acute myocardial infarction after cardiopulmonary resuscitation. J Am Coll Cardiol. 1996;28(5): $1220-1225$.

78. Hejl CG, Astier HT, Ramirez JM. Prevention of preanalytical falsepositive increases of cardiac troponin I on the Unicel DxI 800 analyzer Clin Chem Lab Med. 2008;46(12):1789-1790.

79. Makaryus AN, Makaryus MN, Hassid B. Falsely elevated cardiac troponin I levels. Clin Cardiol. 2007;30(2):92-94.

80. Shayanfar N, Bestmann L, Schulthess G, Hersberger M. False-positive cardiac troponin $\mathrm{T}$ due to assay interference with heterophilic antibodies. Swiss Med Wkly. 2008;138(31-32):470.
Vascular Health and Risk Management

\section{Publish your work in this journal}

Vascular Health and Risk Management is an international, peerreviewed journal of therapeutics and risk management, focusing on concise rapid reporting of clinical studies on the processes involved in the maintenance of vascular health; the monitoring, prevention and treatment of vascular disease and its sequelae; and the involvement of

\section{Dovepress}

metabolic disorders, particularly diabetes. This journal is indexed on PubMed Central and MedLine. The manuscript management system is completely online and includes a very quick and fair peer-review system, which is all easy to use. Visit http://www.dovepress.com/ testimonials.php to read real quotes from published authors 